\title{
Sporadic hotspots for physico-chemical retention of aquatic organic carbon: from peatland headwater source to sea
}

\author{
Sheila M. Palmer ${ }^{1}$ - Chris D. Evans ${ }^{2}$ Pippa J. Chapman ${ }^{1}$ - Annette Burden ${ }^{2}$. \\ Tim G. Jones ${ }^{3} \cdot$ Tim E. H. Allott ${ }^{4} \cdot$ Martin G. Evans ${ }^{4} \cdot$ Catherine S. Moody $^{5}$. \\ Fred Worrall ${ }^{5} \cdot$ Joseph Holden ${ }^{1}$
}

Received: 23 December 2014/Accepted: 6 November 2015/Published online: 23 December 2015

(C) The Author(s) 2015. This article is published with open access at Springerlink.com

\begin{abstract}
Few studies have quantified the role of instream processes on net dissolved and particulate organic carbon (DOC and POC, respectively) export from peatland catchments, and those that have offer conflicting evidence. In this study, we evaluated evidence for active organic matter processing under field conditions, via a coordinated campaign across four UK catchments with peatland headwaters, targeted on potential 'hotspots' and 'hot moments' of physico-chemical carbon cycling. We hypothesised that specific hotspots and hot moments would occur where waters enriched with DOC and POC sourced from headwaters are exposed to: (1) mixing with freshwaters of different $\mathrm{pH}$, conductivity and metal concentrations; and (2) mixing with seawater during autumn when DOC concentrations were at their highest. We observed instances of
\end{abstract}

This article is part of the special issue 'Carbon Cycling in Aquatic Ecosystems'

Electronic supplementary material The online version of this article (doi:10.1007/s00027-015-0448-x) contains supplementary material, which is available to authorized users.

Sheila M. Palmer

s.m.palmer@leeds.ac.uk

1 Water@leeds, School of Geography, University of Leeds, Leeds LS2 9JT, UK

2 Centre for Ecology and Hydrology, Environment Centre Wales, Deiniol Road, Bangor LL57 2UW, UK

3 School of Biological Sciences, Bangor University, Deiniol Road, Bangor LL57 2UW, UK

4 School of Environment, Education and Development, University of Manchester, Manchester M13 9PL, UK

5 Department of Earth Sciences, Science Laboratories, Durham University, Durham DH1 3LE, UK
POC removal in headwaters, and potential for rapid conversion between dissolved and particulate carbon forms and for net removal of peat-derived carbon at confluences further downstream (where observed, on the order of $52-75 \%$ for POC, and 5-44 \% for DOC). Estuary transect surveys indicated that up to $30 \%$ of fluvial DOC can be removed under high flow conditions. However, in the majority of cases concentrations remained within the range that would be expected based on conservative transport. These findings indicate that rapid (e.g. solubility-related) processes within the river system may be important but sporadic, thus are unlikely to provide major removal pathways for peat-derived organic carbon.

Keywords DOC $\cdot$ POC $\cdot$ Peat $\cdot$ Abiotic processing . Estuarine mixing

\section{Introduction}

Terrestrially-derived dissolved organic carbon (DOC) comprises the bulk of fluvial carbon (C) export in most peat-dominated upland headwaters in the UK (typically 87-93\% of total fluvial C; Billett et al. 2006; Dawson et al. 2004). The remaining components of fluvial $C$ export are particulate organic carbon (POC) and dissolved inorganic $\mathrm{C}$ (DIC) species: bicarbonate $\left(\mathrm{HCO}_{3}{ }^{-}\right)$carbonate $\left(\mathrm{CO}_{3}{ }^{2-}\right)$ or gaseous $\mathrm{CO}_{2}$, depending on $\mathrm{pH}$. Heavily eroded peatlands are significant contributors of POC to rivers and streams, and in degraded environments POC may be the main contributor to fluvial C export (Pawson et al. 2012). While dissolved gaseous $\mathrm{C}$ sourced from peaty soils is readily lost from the stream system to the atmosphere (Hope et al. 2001), the fate of organic forms of fluvial $\mathrm{C}$ is more complex and may have a significant climate forcing 
effect if processes within the water column convert POC and DOC to $\mathrm{CO}_{2}$.

DOC and POC are potential sources of energy to aquatic organisms, and may be consumed either in the water column (e.g. Bernhardt and McDowell 2008) or in stream beds or the hyporheic zone (Fiebig and Lock 1991). However, biotic organic matter cycling is strongly dependent on availability of nutrients such as nitrate (Taylor and Townsend 2010; Wickland et al. 2012) and sensitive to organic matter 'quality' (Mann et al. 2012). On an annual basis, 13-21\% of the DOC in the Yukon river and its tributaries was estimated to be biodegradable (Wickland et al. 2012). Biodegradability (as assessed in 28-day incubations) was greatest in winter when the ratio of DOC to concentrations of inorganic $\mathrm{N}$ was lowest, suggesting that the relative availability of $\mathrm{N}$ is an overriding control on biotic DOC processing (Wickland et al. 2012). Wickland et al. (2012) also found that the proportion of biodegradable DOC (\%BDOC) was significantly related to DOC 'quality' as inferred by optical and fluorescence proxy measurements. In tributaries of the Kolyma basin that drains to the Arctic Ocean, Mann et al. (2012) found that biological removal of DOC was strongly and positively correlated with fresh plant-derived $\mathrm{C}$ and ammonium $\left(\mathrm{NH}_{4}{ }^{+}-\mathrm{N}\right)$ concentrations and negatively correlated with low molecular weight fulvic-like $\mathrm{C}$, assumed to be a more degraded fraction of the DOC pool. In peatland streams, nutrient levels are low, so biological processing may be slow relative to in-stream residence times. For catchments with varying proportions of peat cover in northern Finland, potential DOC biodegradation rates in laboratory incubations (nutrients were added to prevent nutrient limitation) ranged from 4.1 to $17.9 \%$ (Hulatt et al. 2014) and averaged $8.89 \%$ (Asmala et al. 2014a) during incubations lasting 55 and 39 days, respectively. In a batch experiment Stutter et al. (2013) found that similar to other northern rivers, a maximum $19 \%$ of DOM isolated from a Scottish moorland stream was biodegradable during 41-days incubation, and that the proportion of DOM decomposed could be predicted by DOM quality and ${ }^{15} \mathrm{~N}$ content. Overall, these studies suggest that given time (on the order of days) and sufficient nutrients, biodegradation potentially removes up to $20 \%$ of DOC from the water column in northern rivers.

DOC and POC may also be lost to bottom sediments through adsorption to mineral particles or flocculation (Sharp et al. 2006, McKnight et al. 2002), yet the potential for removal of fluvial $\mathrm{C}$ by such abiotic processes is poorly constrained and has generally received little attention. In a field experiment where DOC-rich waters were added to iron (Fe)-rich waters, fulvic acids were preferentially removed at a very rapid rate (of the order of milliseconds; McKnight et al. 2002). Adsorption and/or co-precipitation of DOC with Fe may therefore constitute a sink for DOC in upland waters, although re-suspension or dissolution may occur if conditions are favourable, and have been linked to seasonal variation in lake DOC concentrations in Esthwaite Water, Northern England (Hamilton-Taylor et al. 1996). Photo-mediated oxidation of aquatic DOC also potentially converts fluvial organic $\mathrm{C}$ to $\mathrm{CO}_{2}$, and is recognised as an important process in lakes (Anesio and Graneli 2004). There is experimental evidence that photo-oxidation may be important for Fe-rich and acidic streams (Molot et al. 2005; Wu et al. 2005), and recent work undertaken by Moody et al. (2013) suggests high rates of photo-mediated degradation of peat-derived organic matter.

Few studies have quantified the role of in-stream processes on net DOC and POC export from upland catchments, and those that have offer conflicting evidence. Some studies (Dawson et al. 2004; Temnerud et al. 2007) found little evidence of DOC processing, whilst other studies have suggested removal rates in the region of 10-20\% within small headwater catchments (Billett et al. 2006; Dawson et al. 2001), and higher rates in larger catchments (Algesten et al. 2004; Jonsson et al. 2007) and under field experimental conditions (up to $76 \%$ decline in DOC; Moody et al. 2013). There have also been some studies providing evidence that DOC can be removed from the water column during water transit through the freshwaterseawater interface (Spencer et al. 2007; Uher et al. 2001), although once again other studies in different estuarine systems have concluded that DOC is fairly unreactive (Alvarez-Salgado and Miller 1998; Amon and Meon 2004). Sholkovitz et al. (1978) suggested that the humic acid component of DOC is most susceptible to flocculation, which could explain these differences. In support of this idea, Bowers et al. (2004) found a strong negative correlation between salinity and coloured dissolved organic matter (CDOM), as inferred by light absorbance at $440 \mathrm{~nm}$ wavelength, in an estuary and assumed to be of terrestrial plant origin. Recent experiments also have shown a change in dissolved organic matter (DOM) quality in river water treated with saline solutions. Kritzberg et al. (2014) found that high salinity caused a decrease in humic acids and aromatic DOM (as indicated by E4/E6 and SUVA 254 , respectively), and riverine average molecular weight has been observed to decrease even at low salinities (1-6; Asmala et al. 2014b). Similarly in freshwaters it is the hydrophobic component of humic and fulvic acids that is the most reactive (Sharp et al. 2006), and in coloured waters this fraction constitutes $60-80 \%$ of the total DOC (Malcolm 1985), indicating significant potential for flocculation when DOC-rich waters enter estuaries. Evidence for POC removal in peat-influenced freshwater systems is limited, with estimates ranging from $<5$ to $>50 \%$ removal obtained from different studies (Dawson et al. 2004, 2012; 
Worrall and Moody 2014). Pawson et al. (2012) demonstrated rapid removal of POC and decreasing POC:DOC ratios in headwaters of eroding peatlands, indicating either deposition of POC to bottom sediments or conversion of POC to DOC.

There are therefore various potential mechanisms for the removal of peat-derived DOC and POC from freshwaters, but 'hot spots' of biogeochemical cycling are most likely to occur when converging hydrological flowpaths deliver appropriate reactants to DOC- or POC-rich waters (McClain et al. 2003). Similarly, there may be occasions of rapid reactivity when waters are particularly enriched with DOC/POC ('hot moments'; sensu McClain et al. 2003). In upland peaty catchments, 'hot moments' of DOC delivery to streams have been observed to occur during late summer and autumn as a result of temperature-related production in soils and subsequent 'flushing' during high flow events (Chapman et al. 2010). Concentrations of POC in peaty headwaters also increase during high flow events (Pawson et al. 2008).

In light of the dearth of information and conflicting findings on the fate of peat-derived DOC and POC within river systems, the aim of this paper is to evaluate evidence for rapid, organic matter processing under field conditions, via a coordinated set of field measurements across four catchments targeted on potential 'hotspots' of physicochemical $\mathrm{C}$ cycling. We hypothesised that specific hotspots would occur where DOC-and POC-rich waters are exposed to: (1) mixing with river waters of different $\mathrm{pH}$, conductivity, and metal concentrations; and (2) mixing with seawater during periods when delivery from headwaters is highest during autumn. The first hypothesis, affecting freshwaters, was addressed via synoptic survey of peatland river systems. Mixing of freshwater and seawater was addressed through transect sampling at an estuarine site.

\section{Methods}

\section{Catchment site selection and sampling}

Three peatland regions (and four catchments) in northern England and one in North wales were included in the study (Fig. 1 and Table S1): The Tees catchment in the North Pennines; the Nidd catchment in the Central Pennines, the Etherow and Ashop catchments in the Peak District, and the Conwy catchment in North Wales. Within each study region, sites were selected to capture the change in physico-chemical conditions from peatland headwaters, through the transition from peaty to mineral soils further downstream. Samples were collected above and below confluences between streams (12 confluences in total) and from the upper and lower ends of nine linear river reaches, varying in length from approximately $0.4 \mathrm{~km}$ to over $2 \mathrm{~km}$ (Fig. 1). Stream waters in the four regions were sampled within 2 weeks of each other on three occasions (early March, late June/early July and late September/early October) in both 2011 and 2012. The majority of the sampling sites were ungauged for river flow, although flow data were available for some sites in the Tees and the Nidd regions. At all sites, sampling trips coincided with very low flow conditions in 2011 compared to 2012.

\section{Estuary site selection and sampling}

For the estuary study we focused on that of the Afon Conwy in North Wales. Compared to the Pennine river systems, the Conwy catchment is relatively small, with a large peatland area and little urban influence, so that a high proportion of organic matter entering the estuary is likely to be derived from peaty sources in the headwaters of the catchment. The site therefore provides a suitable location at which to evaluate the potential for processing of organic matter through the freshwater-seawater transition. The estuary itself is shallow, with a large tidal range, so that tidal volume exchange exceeds average river flows by a factor of 20 (Simpson et al. 2001). Around $10 \mathrm{~km}$ of the river are tidally influenced, providing the opportunity to sample across a long salinity gradient. A total of five estuary transect surveys were undertaken, in October 2010, March 2011, June 2011, September 2011 and September 2012 (the focus on autumn sampling reflected the relatively high inputs of peat-derived DOC that occur at this time). During each sampling trip, a boat was used to collect samples from mid-river, from freshwater through to seawater at the estuary mouth. With the exception of October 2010, all surveys were undertaken close to periods of peak tidal amplitude. Samples were collected at or close to high tide (for logistical reasons, as the boat could not be taken up-river at low tide) and a conductivity probe was used to identify sampling points spanning a full range of freshwater:seawater ratios. Consequently, samples were not necessarily collected at the same locations on each trip, although they extended across approximately the same length of river (about $15 \mathrm{~km}$, from just downstream of the tidal limit to the estuary mouth).

\section{Stream and estuarine chemistry}

Stream temperature, $\mathrm{pH}$ and conductivity were measured in the field at the time of collection. All dissolved species were determined within a few days of collection on samples filtered through $0.45 \mu \mathrm{m}$ nylon filters with the exception of POC. Total dissolved carbon (DC) and DIC were analysed by thermocatalytic oxidation (Analytik Jena Multi NC2100) and DOC determined as the difference 


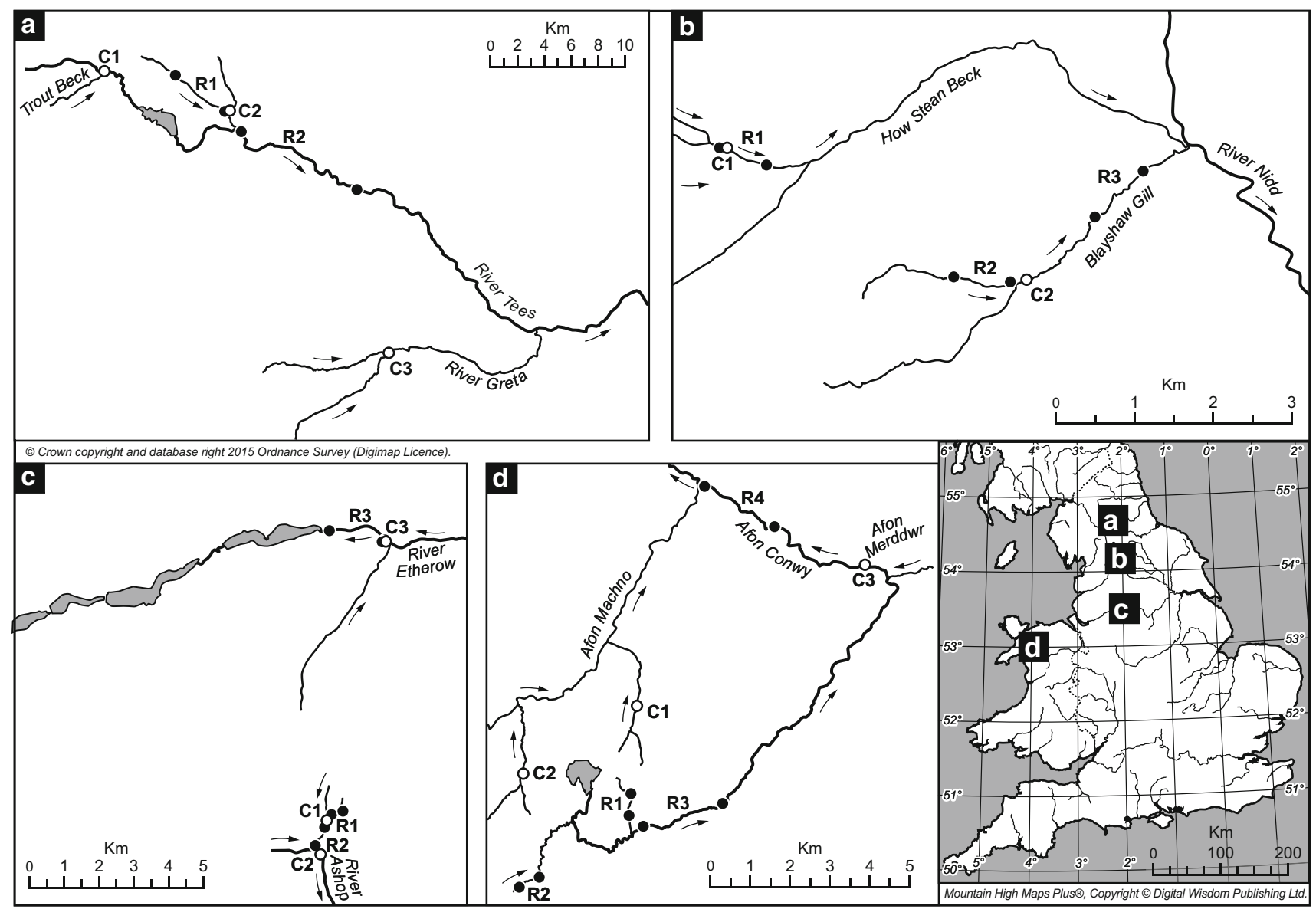

Fig. 1 Location of the four regions within the UK (bottom right) and schematic maps of the sites sampled in this study: a Tees; b Nidd; c Peak; and d Conwy. Open symbols indicate locations of confluence

between DC and DIC. A certified reference material (QC WWW4A, VKI Reference Materials, Denmark) was used to verify DOC concentration and the precision of repeated analyses was within $5 \%$ for DOC and $10 \%$ for DIC. The anions chloride $\left(\mathrm{Cl}^{-}\right)$, nitrate $\left(\mathrm{NO}_{3}{ }^{-}\right)$and sulphate $\left(\mathrm{SO}_{4}{ }^{2-}\right)$ were determined by ion chromatography (Dionex ICS 3000 DC). Total dissolved metals and metalloids $(\mathrm{Ca}, \mathrm{Mg}, \mathrm{Na}$, $\mathrm{K}, \mathrm{Al}, \mathrm{Fe}, \mathrm{Mn}$ and $\mathrm{Si}$ ) were determined by ICP-OES (Perkin Elmer 5300DV) and no assumption is made regarding charge. Dissolved inorganic nitrogen (DIN: $\mathrm{NH}_{4}$ $\mathrm{N}$ plus $\mathrm{NO}_{3}-\mathrm{N}$ ) was determined colorimetrically (Skalar $\mathrm{SAN}++$ continuous flow autoanalyser). Particulate organic carbon was determined from the mass of material retained on filtering through a pre-washed and pre-ashed $0.7 \mu \mathrm{m}$ $\mathrm{GF} / \mathrm{F}$ filter following combustion at $500{ }^{\circ} \mathrm{C}$ to determine the organic fraction. Absorbance in the UV-visible range was measured by scanning spectrophotometer (Jacso V630) and the specific UV absorbance @254 nm divided by DOC concentration $\left(\mathrm{SUVA}_{254}\right)$ was used as an indicator of DOC aromaticity (Weishaar et al. 2003). Estuarine samples were analysed for conductivity, DOC, POC and sampling points; closed symbols indicate locations of straight reach sampling points; arrows indicate direction of flow

UV-vis absorbance only. Method detection limits for DOC, DIC and POC were $1.3,2.5$ and $0.9 \mathrm{mg} \mathrm{L}^{-1}$, respectively.

\section{Stream data analysis}

Changes in fluvial $\mathrm{C}$ concentrations and other chemical variables along reaches were calculated as the difference in concentration between downstream and upstream sites (such that a negative value indicates an apparent net loss or decrease in concentration at the downstream site). For each individual reach, differences across all sampling dates were tested for significance using Wilcoxon Signed-Ranks test.

For stream confluences, fluvial POC and DOC concentrations in confluence outflows were predicted using solute mixing models and/or flux models where discharge data were available (Nidd confluences; see below). The mixing models were developed using a suite of measured solute tracers $\left(\mathrm{Cl}^{-}, \mathrm{SO}_{4}{ }^{2+}, \mathrm{Ca}, \mathrm{K}, \mathrm{Mg}, \mathrm{Na}\right.$ and $\left.\mathrm{Si}\right)$ to estimate the contribution to confluence outflow of each confluence inflow: 
$\%$ Inflow $1=\left(\left[\mathrm{C}_{\mathrm{I} 2}\right]-\left[\mathrm{C}_{\mathrm{O}}\right]\right) /\left(\left[\mathrm{C}_{\mathrm{I} 2}\right]-\left[\mathrm{C}_{\mathrm{I} 1}\right]\right) \times 100$

where $\left[\mathrm{C}_{\mathrm{I}}\right],\left[\mathrm{C}_{\mathrm{I} 2}\right],\left[\mathrm{C}_{\mathrm{O}}\right]=$ concentration of solute tracer in the inflows 1 and 2 and in the outflow, respectively. Solutes that were likely to show non-conservative behaviour in streams (DIN) or that are known to have a strong affinity with $\mathrm{DOC}(\mathrm{Fe}, \mathrm{Al})$ were excluded from the model.

This mixing model approach was applied to each tracer. The mixing ratio was calculated for each individual tracer and was rejected if the resulting model estimated a flow contribution for one inflow of more than $100 \%$ or less than zero. If only two solutes remained after this step, both were used in the final model. If more than two solutes remained, the median of the remaining mixing ratios was calculated, and any single solute models that were more than $15 \%$ different from the median on any date were also rejected (Schemel et al. 2006). All other solutes were retained and their median mixing ratios were used in the final model. This exercise was repeated for all confluences. In the Nidd catchment, stream flow was also measured at the time of sampling, either by salt dilution gauging (Nidd Reach $1 /$ confluence 1 ) or continuous river flow gauging on a rated reach (Nidd Reach 2/confluence 2).

Instantaneous DOC, POC and DIC fluxes were calculated at the time of sampling as the product of measured concentration and discharge, and upstream $\mathrm{C}$ flux data were used to predict $\mathrm{C}$ fluxes downstream of confluences based on a conservative mixing model:

$\mathrm{C}_{\text {Oexp }}=\left(\mathrm{F}_{\mathrm{I} 1}+\mathrm{F}_{\mathrm{I} 2}\right) /\left(\mathrm{Q}_{\mathrm{I} 1}+\mathrm{Q}_{\mathrm{I} 2}\right)$

where $\mathrm{F}_{\mathrm{I} 1}, \mathrm{~F}_{\mathrm{I} 2}$ are the instantaneous fluxes $\left(\mathrm{mg} \mathrm{s}^{-1}\right)$ of fluvial $C$ in inflows $(1,2)$ upstream of the confluence; $\mathrm{Q}_{\mathrm{I} 1}$, $\mathrm{Q}_{\mathrm{I} 2}$ are the stream flows $\left(\mathrm{L} \mathrm{s}^{-1}\right)$ of inflows $(1,2)$ at the time of sampling; $\mathrm{C}_{\text {Oexp }}$ is the expected fluvial $\mathrm{C}$ concentration in the outflow assuming conservative mixing and no gain/ loss of water across the confluence.

Along straight reaches, the instantaneous fluxes were used to estimate the expected minimum downstream concentration of fluvial $\mathrm{C}$ assuming no further inputs along the reach:

$\mathrm{C}_{\min }=\mathrm{F}_{1} / \mathrm{Q}_{2}$

where $\mathrm{F}_{1}$ is the instantaneous flux $\left(\mathrm{mg} \mathrm{s}^{-1}\right)$ of fluvial $\mathrm{C}$ at the upstream start of the reach and $\mathrm{Q}_{2}$ is the stream flow $\left(\mathrm{mg} \mathrm{L}^{-1}\right)$ at the downstream end of the reach at the time of sampling.

\section{Estuarine data analysis}

Data were analysed by plotting DOC and POC concentrations against lab-measured conductivity, as a proxy for salinity, i.e. sea-water content. If determinands follow a linear relationship with conductivity, this indicates conservative mixing as river water is diluted by seawater through the estuary (Spencer et al. 2007). A concave nonlinear relationship suggests net removal, whilst a convex non-linear relationship would suggest net production. To estimate deviation from a conservative mixing line, and thus the magnitude of any removal or production within the estuary, DOC and POC concentrations were linearly regressed against conductivity for all samples with conductivity higher than $20 \mathrm{mS} \mathrm{cm} \mathrm{cm}^{-1}$. This threshold was selected as a consistent (albeit arbitrary) cut-off, in order represent the seaward saline 'half' of the transect (the lowest conductivity value measured at the seaward end of a transect was $41 \mathrm{mS} \mathrm{cm}^{-1}$ ). In no case did we observe any clear evidence of non-conservative DOC or POC mixing above the $20 \mathrm{mS} \mathrm{cm}^{-1}$ threshold. The fitted line was then extrapolated back to the freshwater end of the transect and compared to actual measured concentrations. Absorbance at $254 \mathrm{~nm}\left(\mathrm{Abs}_{254}\right)$ was included as a tracer for humic (i.e. peat or other terrestrially derived) DOC, as opposed to less coloured DOC (such as marine DOC) potentially present in the bulk DOC measurements.

\section{Results}

\section{Patterns of freshwater fluvial $\mathrm{C}$ by sample date and region}

There was considerable variability in DOC concentrations and to a lesser extent POC concentrations both between sampling dates and across regions (Table 1). DOC concentrations were lowest during March 2011 and highest during summer 2012 coincident with low $\mathrm{pH}$ and conductivity. POC concentrations were often below detection limits during the March samplings in both years and highest during autumn. Both DOC and POC median concentrations, and median $\mathrm{pH}$ and conductivity, were lowest in the Conwy catchment, but there were no differences between other regions (Table 1). DIC was occasionally high at sites in the Nidd and Tees with calcareous geology, and low elsewhere. $\mathrm{SUVA}_{254}$ values did not exhibit much variation between sampling dates or between regions. DIN concentrations were very low and frequently below detection limits, confirming the low nutrient status of these catchments.

\section{Changes in freshwater fluvial $\mathrm{C}$ concentrations and fluxes across linear reaches}

All forms of fluvial $\mathrm{C}$ exhibited some degree of concentration change along reaches, although for the most part these changes were small and statistically insignificant. In five out of the twelve reaches, differences between 


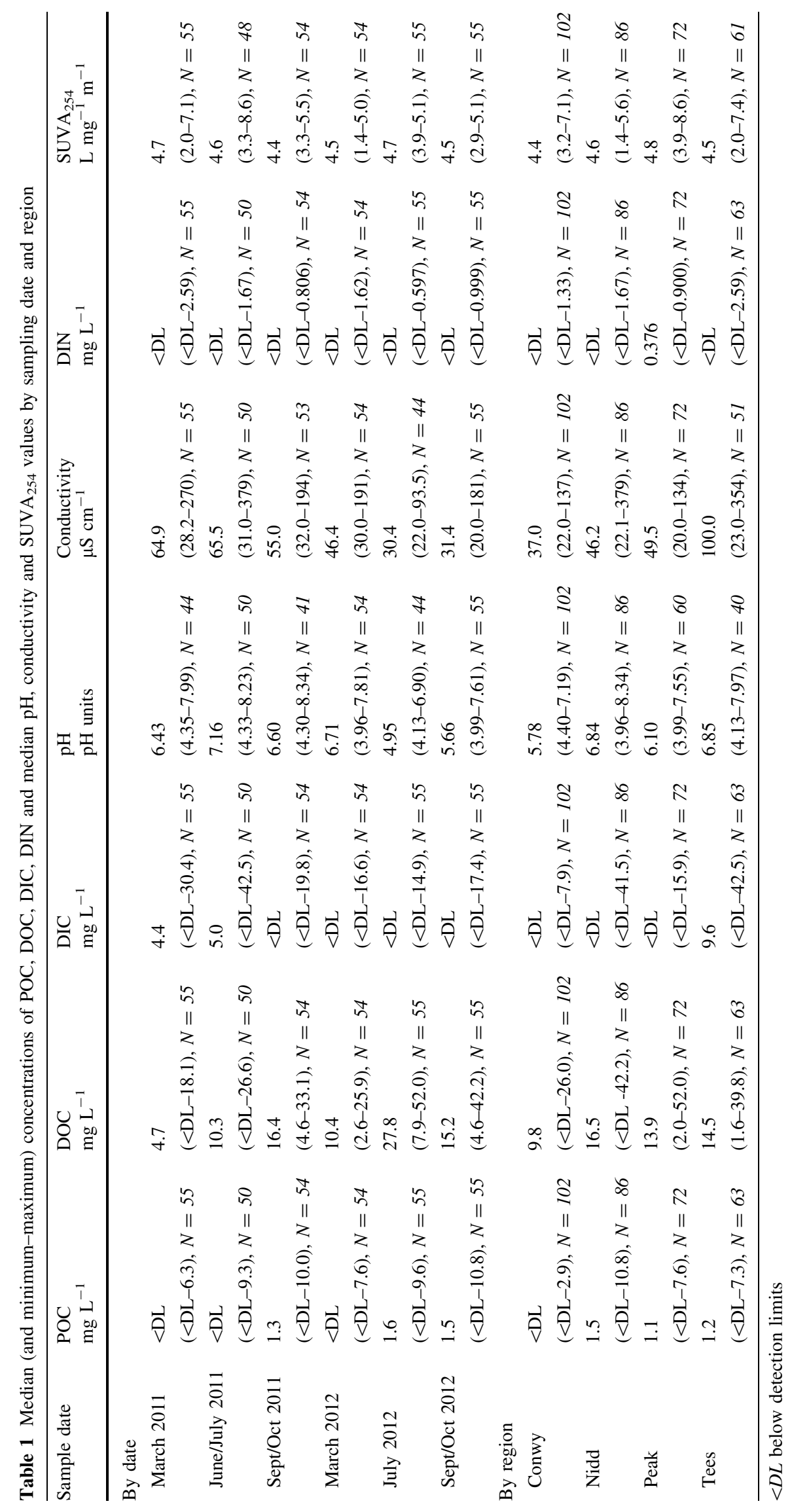


Table 2 Statistically significant median differences between upstream and downstream fluvial $\mathrm{C}$ concentrations, all dates pooled

\begin{tabular}{|c|c|c|c|c|c|}
\hline Region & Reach & $\Delta \mathrm{POC} \mathrm{mg} \mathrm{L}^{-1}$ & $\Delta \mathrm{DOC} \mathrm{mg} \mathrm{L}{ }^{-1}$ & $\Delta \mathrm{DIC} \mathrm{mg} \mathrm{L}{ }^{-1}$ & $\Delta$ SUVA $_{254} \mathrm{~L} \mathrm{mg}^{-1} \mathrm{~m}^{-1}$ \\
\hline \multirow[t]{4}{*}{ Conwy } & 3 & 0 & -1.5 & 0 & 0.1 \\
\hline & & & $\mathbf{P}=\mathbf{0 . 0 3}$ & & ns \\
\hline & 4 & 0.2 & 0.2 & 0.3 & -0.1 \\
\hline & & $\mathbf{P}=\mathbf{0 . 0 3}$ & ns & $\mathbf{P}=\mathbf{0 . 0 3}$ & ns \\
\hline \multirow[t]{2}{*}{ Nidd } & 1 & -0.9 & -1.3 & 0.2 & 0.1 \\
\hline & & $\mathbf{P}=\mathbf{0 . 0 3}$ & ns & & \\
\hline \multirow[t]{4}{*}{ Peak } & 1 & -0.8 & -6.3 & 0 & 0.1 \\
\hline & & ns & $\mathbf{P}=\mathbf{0 . 0 3}$ & & \\
\hline & 2 & -0.6 & -2.22 & 0 & -0.1 \\
\hline & & ns & $\mathbf{P}=\mathbf{0 . 0 3}$ & & ns \\
\hline
\end{tabular}

Statistically significant differences are indicated in bold

$\mathrm{N}=6$ all reaches

Table 3 Spearman's rank correlations of reach-scale changes in POC and DOC with other solutes

\begin{tabular}{lllllllllllll}
\hline & POC & DOC & DIN & pH & Conductivity & $\mathrm{Cl}^{-}$ & $\mathrm{Al}$ & $\mathrm{Ca}$ & $\mathrm{Fe}$ & $\mathrm{Mg}$ & $\mathrm{Na}$ & $\mathrm{Si}$ \\
\hline POC & - & $\mathbf{0 . 3 0}$ & 0.11 & $\mathbf{- 0 . 2 6} *$ & $\mathbf{- 0 . 2 4} *$ & $\mathbf{0 . 2 8} *$ & 0.08 & -0.10 & $\mathbf{0 . 3 1} * *$ & $\mathbf{- 0 . 4 1} * * *$ & -0.01 & $-\mathbf{0 . 2 7} *$ \\
DOC & $\mathbf{0 . 3 0}^{*}$ & - & 0.12 & -0.06 & 0.19 & 0.09 & $\mathbf{0 . 3 0}$ & -0.10 & $\mathbf{0 . 5 2} * * *$ & $\mathbf{- 0 . 4 9 * * *}$ & $-\mathbf{0 . 3 6} * *$ & $-\mathbf{0 . 4 6} * * *$ \\
\hline
\end{tabular}

Text in bold indicates statistically significant correlations

$* \mathrm{P}<0.05 ; * * \mathrm{P}<0.01 ; * * * \mathrm{P}<0.001$

Table 4 Means and standard deviations (in parentheses) of flow contributions from inflow 1 and mean percentage differences between observed and predicted fluvial $\mathrm{C}$ concentrations in confluence outflows

\begin{tabular}{llllll}
\hline Region & Model & Mean contribution & \multicolumn{2}{l}{ Observed minus predicted as percentage observed } \\
\cline { 5 - 6 } & & \% Inflow 1 & POC & DOC & DIC \\
\hline Conwy C2 & Solute mixing $\left(\mathrm{SO}_{4}{ }^{2-}, \mathrm{Mg}\right)$ & $55(15)$ & $-2.1(2.9)$ & $-9.2(8.0)$ & $-0.4(1.1)$ \\
Conwy C3 & Solute mixing $\left(\mathrm{SO}_{4}{ }^{2-}, \mathrm{Mg}, \mathrm{Si}\right)$ & $66(14)$ & $-0.8(23.0)$ & $-9.5(18.6)$ & $-5.0(21.0)$ \\
Nidd C1 & Instantaneous flux & $47(14)$ & $177(406)$ & $25.4(37.2)$ & $1.3(1.5)$ \\
Nidd C2 & A. Solute mixing $(\mathrm{K}, \mathrm{Mg})$ & $71(8)$ & $12.1(22.1)$ & $-2.2(2.3)$ & $-0.7(3.2)$ \\
& B. Instantaneous flux & $84(3)$ & $16.1(23.1)$ & $-0.9(3.9)$ & $-3.6(5.5)$ \\
Peak C1 & Solute mixing $\left(\mathrm{Cl}{ }^{-}, \mathrm{Na}, \mathrm{Si}\right)$ & $47(4)$ & $-43.1(31.6)$ & $3.2(4.4)$ & $1.3(6.4)$ \\
Peak C2 & Solute mixing $(\mathrm{Ca}, \mathrm{Mg})$ & $49(4)$ & $12.3(60.4)$ & $5.5(11.8)$ & $-7.2(7.9)$ \\
Peak C3 & Solute mixing $\left(\mathrm{Cl}^{-}, \mathrm{Ca}, \mathrm{Mg}, \mathrm{Na}\right)$ & $49(9)$ & $-8.4(36.9)$ & $0.0(6.2)$ & $-3.8(9.4)$ \\
Tees C2 & Solute mixing $(\mathrm{Ca}, \mathrm{Mg})$ & $85(5)$ & $2.0(27.7)$ & $23.2(63.4)$ & $-1.6(5.3)$ \\
Tees C3 & Solute mixing $\left(\mathrm{Cl}{ }^{-}, \mathrm{Na}\right)$ & $63(10)$ & $74.0(147)$ & $-7.2(13.0)$ & $15.9(3.3)$ \\
\hline
\end{tabular}

Predicted concentrations were calculated assuming conservative mixing using either a solute mixing model or an instantaneous flux model (see "Methods"). $\mathrm{N}=6$ (Conwy C2, C3; Nidd C2A; Peak C3); N = 5 (Nidd C2B; Peak C1, C2; Tees C2); N = 4 (Nidd C1; Tees C3). Negative values indicate observed concentrations were lower than predicted by solute mixing

upstream and downstream fluvial $\mathrm{C}$ concentration were statistically significant, indicating a consistent pattern of $\mathrm{C}$ gain/loss across sampling dates (Table 2). Decreases in C were more frequent than gains, with the largest DOC declines occurring in Conwy reach 3 and Peak reaches one and three, and the largest POC decline occurring in Nidd reach 1. Across all sites and dates, changes in DOC and POC were positively correlated across reaches, and both were negatively correlated with changes in $\mathrm{Mg}$ and $\mathrm{Si}$ and positively with $\mathrm{Fe}$ (Table 3). Changes in POC were also negatively correlated with changes in $\mathrm{pH}$ and conductivity (Table 3). 


\section{Changes in concentrations and fluxes across confluences}

Nine out of the twelve confluences met the criteria for mixing model selection. There were inconsistent results in the performance of mixing models for each confluence in predicting concentrations of solutes that were considered 'conservative' (Table 4). Large standard deviations reflect the variable performance between dates. The greatest differences between observed and predicted conservative solute concentrations occurred in the two Nidd catchments, and there was no clear difference between the performance of flow-based predictions and mixing-model prediction for Nidd C2. The most consistent model performance across sample dates (smallest variability) in terms of solute prediction occurred for the three Peak District confluences, Conwy C3 and Tees C2, where proportional flow contributions from the two inflows were fairly stable over time.
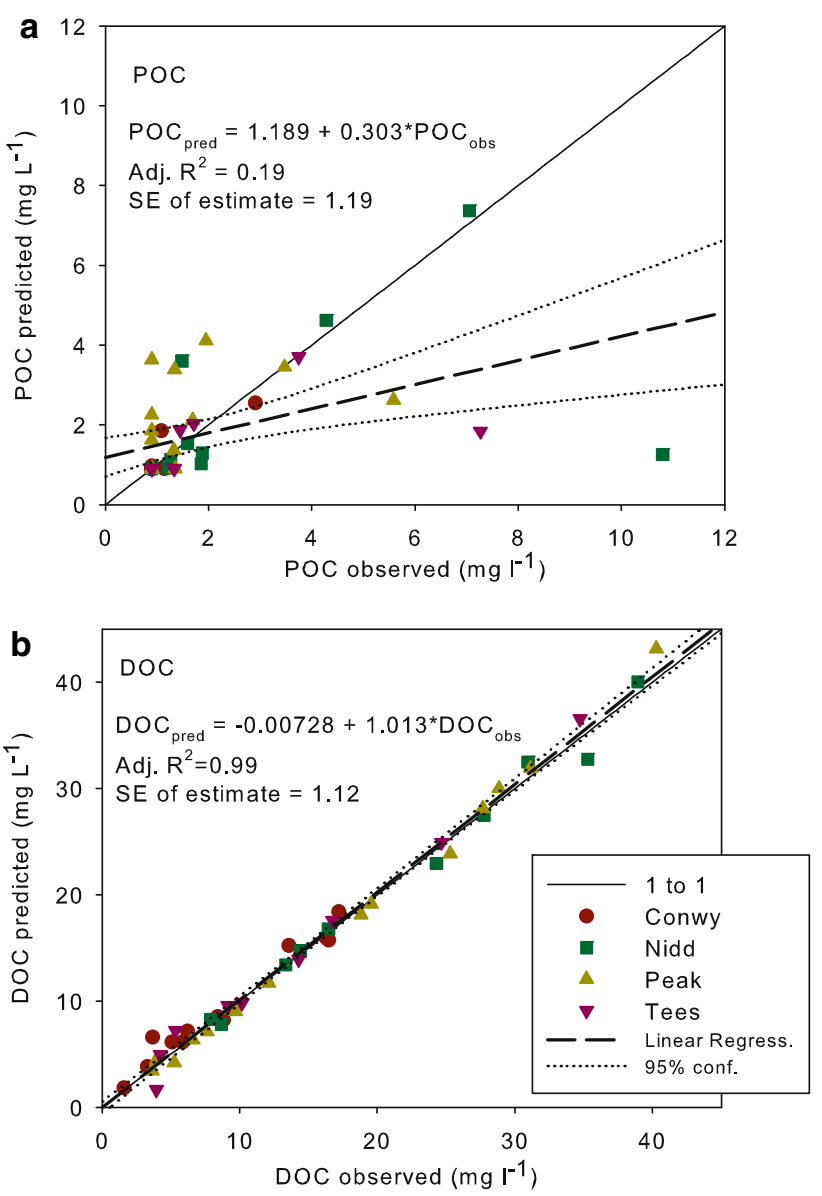

Fig. 2 Concentrations of fluvial $\mathrm{C}$ predicted assuming conservative mixing versus concentrations observed downstream of confluences. Solid lines give the 1-to-1 line; dashed line and equation gives the linear regression between predicted and observed concentrations; dotted lines give $95 \%$ confidence limits for modelled versus observed values. a POC; b DOC
Both losses (predicted $>$ observed) and gains (predicted $<$ observed) in POC occurred at Peak, Nidd and Tees confluences (Fig. 2). Losses that were greater than the nominal cut-off (detection limit; $0.9 \mathrm{mg} \mathrm{L}^{-1}$ ) mostly occurred in the Peak District headwaters, $\mathrm{C} 1$ and $\mathrm{C} 2$, in March and July of both years (1.0-2.7 $\mathrm{mg} \mathrm{L}^{-1} ; 52-75 \%$ ), and were accompanied by smaller increases in DOC concentration. A few relatively large apparent POC gains over expected values also occurred, and at one site (Peak C2; $3.0 \mathrm{mg} \mathrm{L}^{-1}$ ) was accompanied by an almost identical decrease in DOC $\left(2.9 \mathrm{mg} \mathrm{L}^{-1}\right)$. In contrast to POC, percentage DOC gains/losses relative to expected values were small (Fig. 2; Table 4) but actual changes were similar in size to POC losses $\left(1.7-2.9 \mathrm{mg} \mathrm{L}^{-1} ; 5-44 \%\right)$ and gains (2.2-10.8 $\mathrm{mg} \mathrm{L}^{-1}$; 6-136\%).

\section{Changes in concentration in estuarine transects}

Plots of DOC and POC versus conductivity (Fig. 3) show variable patterns of behaviour on different sampling trips. Freshwater inputs to the estuary had DOC concentrations ranging from $2.2-8.7 \mathrm{mg} \mathrm{L}^{-1}$, with the highest concentrations observed in autumn surveys. DOC concentrations at the seaward end of the estuary varied from $1.6-4.3 \mathrm{mg} \mathrm{L}^{-1}$, with the highest concentrations observed in September 2011. The net change in DOC from the freshwater to the seaward end of the transect ranged from -0.03 to $-5.98 \mathrm{mg} \mathrm{L}^{-1}$, and percentage changes from -1 to $-68 \%$ (Table 5 ). In all cases, a conservative mixing line fitted to the higher-salinity samples suggested dilution of DOC across the freshwater-seawater transition. However in most cases this mixing line did not coincide with the observed DOC concentration in the freshwater river. In the October 2010 survey, predicted freshwater concentrations were around $3.4 \mathrm{mg} \mathrm{L}^{-1}(38 \%)$ lower than observed, suggesting significant net DOC removal through the estuary. In contrast, predicted concentrations for the other surveys exceeded observed concentrations by between 0.7 and $2.4 \mathrm{mg} \mathrm{L}^{-1}$, suggesting some net DOC production. Absorbance at $254 \mathrm{~nm}\left(\mathrm{Abs}_{254}\right)$ decreased more consistently and by a greater percentage than DOC ( -81 to $-97 \%$ ), leading to a decrease in $\mathrm{SUVA}_{254}$ from values of 4.48 or higher at the freshwater end of the estuary to 1.55 or lower at the seaward end.

For POC, concentrations were consistently much higher (5.5-10.3 $\left.\mathrm{mg} \mathrm{L}^{-1}\right)$ at the seaward end of the estuary than at the freshwater end $\left(1-2.5 \mathrm{mg} \mathrm{\textrm {L } ^ { - 1 }}\right)$, with percentage increases ranging from 120-930\%. For the October 2010 survey, observed POC concentrations through the estuary lay very close to a conservative mixing line, but in other surveys there was a large amount of deviation from the line, primarily towards the freshwater end of the estuary where large POC peaks were observed in the last three surveys. Despite this high variability across the salinity 
Fig. 3 Plots of DOC (filled circles; dark grey dashed line) and POC (open diamonds; light grey dashed line) versus conductivity (as a measure of sea-water content) for five Conwy estuarine transect surveys. Linear regressions were fit to samples with conductivity $>20 \mathrm{mS} \mathrm{cm}^{-1}$ (indicating transition to seawater). A linear relationship between DOC or POC and conductivity suggests conservative mixing; deviation from this line indicates nonconservative behaviour
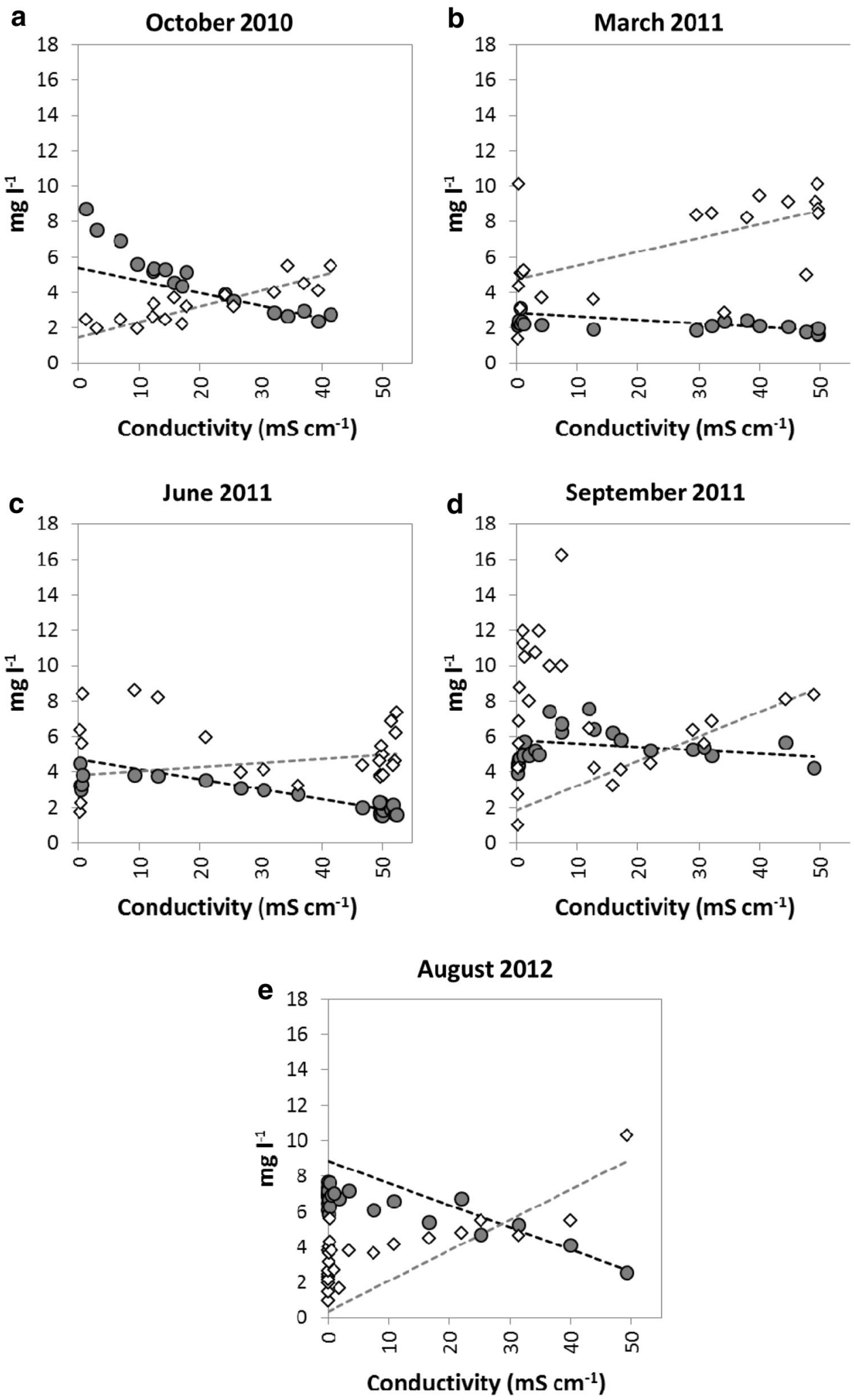
Table 5 The net and percentage change in DOC, $\mathrm{Abs}_{254}, \mathrm{SUVA}_{254}$ and POC from the freshwater to the seaward end of the estuarine transect

\begin{tabular}{|c|c|c|c|c|c|c|c|}
\hline \multirow[t]{2}{*}{ Transect date } & \multicolumn{2}{|l|}{$\triangle \mathrm{DOC}$} & \multicolumn{2}{|l|}{$\Delta \mathrm{Abs}_{254}$} & \multirow{2}{*}{$\begin{array}{l}\Delta \mathrm{SUVA}_{254} \\
\mathrm{~L} \mathrm{mg}^{-1} \mathrm{~m}^{-1}\end{array}$} & \multicolumn{2}{|l|}{$\triangle \mathrm{POC}$} \\
\hline & $\mathrm{mg} \mathrm{L}^{-1}$ & $\%$ & $\mathrm{au} \mathrm{m} \mathrm{m}^{-1}$ & $\%$ & & $\mathrm{mg} \mathrm{L}^{-1}$ & $\%$ \\
\hline Oct 2011 & -5.98 & -68 & -43.0 & -97 & -4.57 & 3.00 & 120 \\
\hline Mar 2011 & -0.16 & -7 & -8.1 & -81 & -3.70 & 7.12 & 518 \\
\hline Jun 2011 & -1.63 & -50 & -13.9 & -85 & -3.49 & 5.63 & 321 \\
\hline Sep 2011 & -0.03 & -1 & -19.8 & -88 & -4.61 & 7.37 & 737 \\
\hline Aug 2012 & -3.90 & -60 & -25.4 & -87 & -3.06 & 9.33 & 933 \\
\hline
\end{tabular}

gradient, observed POC concentrations at the freshwater end of the estuary did not deviate greatly from the value predicted from the conservative mixing line fitted to highsalinity samples.

\section{Discussion}

Fluvial C concentrations were dominated by DOC across all our sites, demonstrating that peaty headwaters are a potential source of energy to downstream aquatic communities. However the high DOC concentrations coupled with persistently low DIN concentrations suggest that these waters are not particularly favourable to biotic cycling. Furthermore, freshwater $\mathrm{SUVA}_{254}$ values were similar across sample dates and regions, and are consistent with highly aromatic DOM from terrestrial inputs (Weishaar et al. 2003) as the main source of fluvial $C$ in these catchments. In contrast, the variations in $\mathrm{pH}$ in rivers and conductivity in the estuary (and in rivers to a lesser extent) provide evidence that a range of chemical conditions existed between regions and sampling dates. Despite this, we did not find evidence for widespread consistent and rapid in-stream and estuarine processing of fluvial C. C losses were confined to a few biogeochemical 'hot spots' in the lower reaches of the catchment and sporadic elsewhere, yet where they occurred the losses were on occasion very high, up to $44 \%$ for DOC loss downstream of confluences and approximately $30 \%$ DOC loss during estuarinefreshwater mixing. These results provide evidence that peat-derived fluvial $\mathrm{C}$ may be highly reactive, and that rapid physico-chemical processes may at times cause losses that are significantly larger than reported at longer timescales for microbial consumption (Dawson et al. 2012; Hulatt et al. 2014; Stutter et al. 2013) or photochemical degradation (Mann et al. 2012; Worrall and Moody 2014).

The strong negative correlation between reach-scale declines in DOC/POC and $\mathrm{Mg}$ and Si suggest that on most occasions apparent fluvial $\mathrm{C}$ losses are due to mixing with unmeasured sub-surface inputs of mineral-rich and POCor DOC-poor waters, rather than in-stream processing. However, the negative correlation of POC with $\mathrm{pH}$ and positive correlation with $\mathrm{Fe}$ may also indicate that at times conditions are favourable to flocculation and settling out of POC from the water column (McKnight et al. 2002; Sharp et al. 2006). For example, in October 2012, a very large decrease in POC (from 10.8 to $0.9 \mathrm{mg} \mathrm{L}^{-1}$ ) was observed in Nidd Reach 1 during moderately high flow. Parts of the Upper Nidd and Peak district catchments are actively eroding and similarly high POC concentrations have previously been observed, particularly during high flow events when POC may constitute up to $80 \%$ of the organic C flux (Pawson et al. 2008). Not much is known about the reactivity and persistence of peat-derived POC in the river system. Dawson et al. (2012) found that less than $3 \%$ of POC was biodegradable during an 18-hour incubation. Sudden loss over relatively short distances as observed in Nidd Reach 1 (less than $1 \mathrm{~km}$ ), with an estimated residence time of less than $15 \mathrm{~min}$, is unlikely to be due to biological processing. The most likely cause is gravitational settling as water moves through natural riffle and pool sequences. Adsorption to or flocculation with colloidal $\mathrm{Fe}$ would encourage removal by increasing the size and mass of particulates in a process similar to that used by water industries for removal of DOC (Sharp et al. 2006). This was one mechanism thought to remove both $\mathrm{Fe}$ and particulate organic matter in the Rio Negro/Solimões confluence in the Amzaon (Aucour et al. 2003). Certainly this could have contributed to the large loss of POC in Nidd reach 1 in October 2012 that was accompanied by a decrease in $\mathrm{Fe}\left(0.855-0.661 \mathrm{mg} \mathrm{L}^{-1}\right)$ and an increase in $\mathrm{pH}$ from $\mathrm{pH}$ 4.4-5.7, which is within the optimal range for Fe-organic matter coagulation (Sharp et al. 2006). Based on discharge measurements taken at the time of sampling the estimated POC removal from the water column during this event equated to $468 \mathrm{mg} \mathrm{C} \mathrm{s}^{-1} \mathrm{~km}^{-1}$. This is an order of magnitude greater than maximum instantaneous $\mathrm{C}$ flux losses (DOC $15.5 \mathrm{mg} \mathrm{C} \mathrm{s}^{-1} \mathrm{~km}^{-1}$, DIC $6 \mathrm{mg} \mathrm{C} \mathrm{s}^{-1} \mathrm{~km}^{-1}$ ) reported for a headwater stream in Scotland (Dawson et al. 2012). Gravitational settling of POC does not constitute a true loss from the system, however, and re-suspension and subsequent down-river transport cannot be ruled out.

At confluences, apparent POC losses were mainly observed in the Nidd and Peak District catchments, which had higher POC concentrations compared to the Conwy and Tees catchments. Large losses (and gains) in Nidd C1 
have to be viewed with some caution because of the poor model performance for this site. The apparent losses at Peak District confluences were not accompanied by losses in metals, or by marked differences in $\mathrm{pH}$ between inflowing tributaries and therefore cannot readily be attributed to flocculation/precipitation. Alternative processes leading to POC loss could include gravitational settling during low flow conditions, conversion of POC to DOC and/or $\mathrm{CO}_{2}$, and removal by filter feeders (Monaghan et al. 2001). In July 2012, a POC gain $\left(3.0 \mathrm{mg} \mathrm{L}^{-1}\right)$ in Peak District $\mathrm{C} 2$ was accompanied by an almost equivalent DOC loss $\left(2.9 \mathrm{mg} \mathrm{L}^{-1}\right)$ suggesting that flocculation of DOC to POC had occurred. These observations are consistent with the concept that POC and DOC are dynamically linked, with conversion from one to the other occurring rapidly within streamwaters. Whereas any observed POC removals and gains occurred in the headwaters, occasional DOC losses were recorded at confluences further downstream (Conwy C2 and C3, Tees C3). These confluences were characterised by water sources draining quite different land areas (mixing of waters draining peats and mineral soils), suggesting that physico-chemical removal processes may also be important for DOC. At Conwy C3, for example, the Merddwr tributary is characterized by alkaline earth metal (median Ca $8.54 \mathrm{mg} \mathrm{L}^{-1}$ and $\mathrm{Mg} 2.09 \mathrm{mg} \mathrm{L}^{-1}$ ) and DIN concentrations (median $0.790 \mathrm{mg} \mathrm{L}^{-1}$ ) that were at least double those of the Conwy entering the confluence (median Ca $4.42 \mathrm{mg} \mathrm{L}^{-1}$; $\mathrm{Mg} 0.825 \mathrm{mg} \mathrm{L}^{-1}$; DIN $0.290 \mathrm{mg} \mathrm{L}^{-1}$ ). Coupled with the generally higher $\mathrm{pH}$ observed at downstream sites, these conditions could favour flocculation and/or microbiological consumption of DOC. In field incubations, Worrall and Moody (2014) observed an average DOC loss of just under $65 \%$ over a 70 -h period (less than $1 \%$ per $\mathrm{h}$ ), attributed to photo-oxidative and microbial consumption. Although not directly comparable to field experiments and observational studies, considerably smaller biodegradation losses have been reported for most laboratory incubations (e.g. $<18 \%$ in 55 days; Hulatt et al. 2014). The largest DOC loss at Conwy C3 $(2.9 \mathrm{mg}$ $\mathrm{L}^{-1}, 44 \%$ of predicted) occurred under low flow conditions. With an estimated velocity of $1 \mathrm{~m} \mathrm{~s}^{-1}$ and a sampling distance of $670 \mathrm{~m}$ from the confluence, this gives a water residence time of 11-12 min and a DOC loss rate of $4 \%$ per min. Whilst microbial and photo-oxidative loss cannot be ruled out in our study, large sporadic losses observed in the field suggest that on the time-scale (typically less than $1 \mathrm{~h}$ ) of water mixing through the confluences and residing in linear reaches of $2-3 \mathrm{~km}$, physicochemical removal processes are likely to be more important.

Results from the five estuary transects undertaken were variable. For DOC, there was clear evidence that terrestrially-derived DOC (much of which is likely to have been peat-derived under autumn high-flow conditions) was removed in the estuary during the October 2010 survey. This was not replicated during the remaining surveys, which suggested a small amount of DOC production within the estuary. However the much greater decreases in $\mathrm{Abs}_{254}$ compared to DOC (and consequent large reductions in $\mathrm{SUVA}_{254}$ ) along the estuarine transects indicate that terrestrially-derived DOC was being consistently and progressively replaced by DOC from other sources during mixing. These observations do not in themselves indicate non-conservative behaviour of terrestrial DOC, because it would be possible to reproduce these changes simply through mixing of two DOC end-members with contrasting SUVA $_{254}$ values. The pattern is, however, consistent with a gradual replacement of DOC from terrestrial sources with DOC from autochthonous sources towards the marine end of the estuary (Huguet et al. 2009). On all dates there was an increase in POC from mid-estuary towards the seaward end, suggesting an influence of phytoplankton which has been shown to be more bioavailable than terrestrial sources of DOC or POC (Sobczak et al. 2002). An analysis of $\mathrm{Abs}_{254}$ against conductivity (data not shown) produced similar relationships to those for DOC concentration, with evidence of non-linear (i.e. non-conservative) change in the October 2010 survey, and linear (conservative) change in all subsequent surveys.

One contributing factor that may help to explain the lack of apparent DOC processing in the estuary (particularly during the March and June sampling trips) may be that terrestrial DOC inputs were too low to allow rapid withinestuary processing to be detected. Another factor is that rapid in situ mobilisation of POC from sediments, and short-term transitions between DOC and POC within the estuary, appeared to obscure the overall signal. Large peaks in POC during several surveys coincided with the "estuarine turbidity maximum', the zone of freshwater-seawater mixing at the head of the rapidly rising tide where sediment re-suspension and biogeochemical processing are greatest (Spencer et al. 2007). As noted above, there is no clear evidence that these peaks were associated with either net production or net removal of POC, but it is possible that either concurrent DOC mobilisation, or the conversion of POC to DOC within the water column, contributed to slight apparent net estuarine DOC production in several of the surveys. A peak in DOC concentrations in the September 2011 survey, which occurred at higher salinity than the peak in POC, may be indicative of some POC to DOC conversion behind the head of the rising tide. These processes are likely to have been maximised by the higher turbulence associated with spring tide conditions when these surveys were undertaken.

In a hydrodynamic modelling study of the Conwy, Robins et al. (2014) have shown that water residence times 
within the estuary far exceed those within the freshwater catchment, due to the large volume of tidal flow compared to the freshwater input. Residence times increase when river flows are low, which can facilitate the 'trapping' of reactive solutes within the estuary. For DOC, however, our data suggest that estuarine processing of peat-derived DOC may be of greatest significance during autumn high flow events, because i) terrestrial inputs of DOC tend to be greatest at this time, and ii) shorter water residence times within the freshwater system limit the potential for photochemical or microbial breakdown of DOC before it reaches the estuary. This hypothesis is consistent with the results of Sholkovitz et al. (1978), who found that the humic acid component of DOC (which is largest in peat runoff) was strongly removed by flocculation during estuarine mixing, whereas the other constituents of DOC were largely unaffected. Consequently, it may only be during high-flow events that untransformed peat-derived DOC enters the estuary, where it is susceptible to flocculation and other removal processes. The untransformed DOC delivered by high flow events may also be relatively enriched in nutrients and therefore potentially more bioavailable (Asmala et al. 2014a). Additional high-flow estuary surveys would clearly be needed to confirm this interpretation and quantify the relative contributions of flocculation and microbial degradation to DOC loss. During low-flow events, however, our results are largely consistent with the results of Moody et al. (2013), suggesting that a high proportion of peat-derived DOC can be photo-degraded within the residence time of UK river systems. Similarly, observations from Sweden have shown a progressive shift from humic 'terrestrial' DOC to compositionally different 'aquatic' DOC during water residence in lakes (Kohler et al. 2013). Our results are also consistent with the previous work of Spencer et al. (2007) who found highest rates of estuarine DOC removal during high flow events, when inflow DOC concentrations and turbidity were highest.

For POC, terrestrial inputs to the estuary were so low that there appears to be little scope for further removal. The physical re-suspension and settling of sediments over tidal cycles within the estuary dominated our observations. Overall we found no evidence for either net removal or net gain of POC across the freshwater-seawater interface.

\section{Conclusions}

Some instances of apparent POC removal were observed in headwater streams, and rapid DOC removal was observed at some confluences further downstream, where peaty water mixes with less acidic and/or nutrient-rich runoff. The results suggest that there is potential for rapid conversion between particulate and dissolved carbon forms, and for net removal of peat-derived $\mathrm{C}$ in some circumstances (where observed, on the order of 52-75\% for POC in stream reaches, and 5-44\% for DOC at confluences).

Overall, however, there was no consistent pattern of DOC or POC removal across the study sites, and in the majority of cases concentrations remained within the range that would be expected for conservative transport. These findings indicate that rapid (e.g. solubility-related) processes within the river system are unlikely to provide major removal pathways for peat-derived organic carbon.

The limited number of estuary transect surveys do not allow definitive conclusions to be reached regarding the reactivity of peat-derived fluvial $\mathrm{C}$ across the freshwaterseawater transition, but results from one survey, supported by previous work, provide tentative evidence that substantial (circa $30 \%$ ) DOC removal can occur when high flow conditions transport relatively unmodified organic matter rapidly from the peatland to the estuary. The most likely fate of this DOC appears to be flocculation and precipitation to sediments within the estuary, but these sediments are highly dynamic in the estuary studied, and the permanence of this sink is thus uncertain.

Acknowledgments This research was conducted as part of project SP1205 funded by the UK Department for Environment, Food and Rural Affairs (Defra). We thank landowners and managers for granting permission to access to field sites. SP thanks M. Gilpin and J. Corr for assistance with field sampling.

Open Access This article is distributed under the terms of the Creative Commons Attribution 4.0 International License (http://crea tivecommons.org/licenses/by/4.0/), which permits unrestricted use, distribution, and reproduction in any medium, provided you give appropriate credit to the original author(s) and the source, provide a link to the Creative Commons license, and indicate if changes were made.

\section{References}

Algesten G, Sobek S, Bergstrom AK, Agren A, Tranvik LJ, Jansson M (2004) Role of lakes for organic carbon cycling in the boreal zone. Glob Change Biol 10(1):141-147

Alvarez-Salgado XA, Miller AEJ (1998) Dissolved organic carbon in a large macrotidal estuary (the Humber, UK): behaviour during estuarine mixing. Mar Pollut Bull 37(3-7):216-224

Amon RMW, Meon B (2004) The biogeochemistry of dissolved organic matter and nutrients in two large Arctic estuaries and potential implications for our understanding of the Arctic Ocean system. Mar Chem 92(1-4):311-330

Anesio AM, Graneli W (2004) Photochemical mineralization of dissolved organic carbon in lakes of differing $\mathrm{pH}$ and humic content. Arch Hydrobiol 160(1):105-116

Asmala E, Autio R, Kaartokallio H, Stedmon CA, Thomas DN (2014a) Processing of humic-rich riverine dissolved organic matter by estuarine bacteria: effects of predegradation and inorganic nutrients. Aquat Sci 76(3):451-463

Asmala E, Bowers DG, Autio R, Kaartokallio H, Thomas DN (2014b) Qualitative changes of riverine dissolved organic matter at low 
salinities due to flocculation. J Geophys Res Biogeosci 119(10):2014JG002722

Aucour AM, Tao FX, Moreira-Turcq P, Seyler P, Sheppard S, Benedetti MF (2003) The Amazon River: behaviour of metals $(\mathrm{Fe}, \mathrm{Al}, \mathrm{Mn})$ and dissolved organic matter in the initial mixing at the Rio Negro/Solimões confluence. Chem Geol 197(1-4):271-285

Bernhardt ES, McDowell WH (2008) Twenty years apart: comparisons of DOM uptake during leaf leachate releases to Hubbard Brook Valley streams in 1979 versus 2000. J Geophys Res Biogeosci 113(G3):G03032. doi:10.1029/2007JG000618

Billett MF, Deacon CM, Palmer SM, Dawson JJC, Hope D (2006) Connecting organic carbon in stream water and soils in a peatland catchment. J Geophys Res Biogeosci 111(G2):G02010. doi:10.1029/2005JG000065

Bowers DG, Evans D, Thomas DN, Ellis K, Williams PJL (2004) Interpreting the colour of an estuary. Estuar Coast Shelf Sci 59(1):13-20

Chapman PJ, McDonald AT, Tyson R, Palmer SM, Mitchell G, Irvine B (2010) Changes in water colour between 1986 and 2006 in the headwaters of the River Nidd, Yorkshire, UK. Biogeochemistry 101(1-3):281-294

Dawson JJC, Bakewell C, Billett MF (2001) Is in-stream processing an important control on spatial changes in carbon fluxes in headwater catchments? Sci Total Environ 265(1-3):153-167

Dawson JJC, Billett MF, Hope D, Palmer SM, Deacon CM (2004) Sources and sinks of aquatic carbon in a peatland stream continuum. Biogeochemistry 70(1):71-92

Dawson JJC, Adhikari YR, Soulsby C, Stutter MI (2012) The biogeochemical reactivity of suspended particulate matter at nested sites in the Dee basin, NE Scotland. Sci Total Environ 434:159-170

Fiebig DM, Lock MA (1991) Immobilization of dissolved organicmatter from groundwater discharging through the stream bed. Freshw Biol 26(1):45-55

Hamilton-Taylor J, Davidson W, Morfett K (1996) The biogeochemical cycling of $\mathrm{Zn}, \mathrm{Cu}, \mathrm{Fe}, \mathrm{Mn}$ and dissolved organic $\mathrm{C}$ in a seasonally anoxic lake. Limnol Oceanogr 41(3):408-418

Hope D, Palmer SM, Billett MF, Dawson JC (2001) Carbon dioxide and methane evasion from a temperate peatland stream. Limnol Oceanogr 46(4):847-857

Huguet A, Vacher L, Relexans S, Saubusse S, Froidefond JM, Parlanti E (2009) Properties of fluorescent dissolved organic matter in the Gironde Estuary. Org Geochem 40(6):706-719

Hulatt CJ, Kaartokallio H, Asmala E, Autio R, Stedmon CA, Sonninen E, Oinonen M, Thomas DN (2014) Bioavailability and radiocarbon age of fluvial dissolved organic matter (DOM) from a northern peatland-dominated catchment: effect of land-use change. Aquat Sci 76(3):393-404

Jonsson A, Algesten G, Bergstrom AK, Bishop K, Sobek S, Tranvik LJ, Jansson M (2007) Integrating aquatic carbon fluxes in a boreal catchment carbon budget. J Hydrol 334(1-2):141-150

Kohler SJ, Kothawala D, Futter MN, Liungman O, Tranvik L (2013) In-lake processes offset increased terrestrial inputs of dissolved organic carbon and color to lakes. Plos One 8(8):e70598. doi:10. 1371/journal.pone.0070598

Kritzberg ES, Villanueva AB, Jung M, Reader HE (2014) Importance of Boreal rivers in providing iron to marine waters. PLoS One 9(9):e107500. doi:10.1371/journal.pone.0107500

Malcolm RL (1985) Geochemistry of stream fulvic and humic substances. In: Aiken GR, McKnight DM, Wershaw RL, MacCarthy P (eds) Humic substances in soil, sediment and water. Geochemistry isolation and characterization. Wiley, New York7, pp 53-86

Mann PJ, Davydova A, Zimov N, Spencer RGM, Davydov S, Bulygina E, Zimov S, Holmes RM (2012) Controls on the composition and lability of dissolved organic matter in Siberia's
Kolyma River basin. J Geophys Res 117:G01028. doi:10.1029/ 2011JG001798

McClain ME, Boyer EW, Dent CL, Gergel SE, Grimm NB, Groffman PM, Hart SC, Harvey JW, Johnston CA, Mayorga E, McDowell WH, Pinay G (2003) Biogeochemical hot spots and hot moments at the interface of terrestrial and aquatic ecosystems. Ecosystems 6(4):301-312

McKnight DM, Hornberger GM, Bencala KE, Boyer EW (2002) Instream sorption of fulvic acid in an acidic stream: a stream-scale transport experiment. Water Resour Res 38(1):1005

Molot LA, Hudson JJ, Dillon PJ, Miller SA (2005) Effect of pH on photo-oxidation of dissolved organic carbon by hydroxyl radicals in a coloured, softwater stream. Aquat Sci 67(2):189-195

Monaghan MT, Thomas SA, Minshall GW, Newbold JD, Cushing CE (2001) The influence of filter-feeding benthic macroinvertebrates on the transport and deposition of particulate organic matter and diatoms in two streams. Limnol Oceanogr 46:1091-1099

Moody CS, Worrall F, Evans CD, Jones TG (2013) The rate of loss of dissolved organic carbon (DOC) through a catchment. J Hydrol 492:139-150

Pawson RR, Lord DR, Evans MG, Allott TEH (2008) Fluvial organic carbon flux from an eroding peatland catchment, southern Pennines, UK. Hydrol Earth Syst Sci 12(2):625-634

Pawson RR, Evans MG, Allott T (2012) Fluvial carbon flux from headwater peatland streams: significance of particulate carbon flux. Earth Surf Proc Land 37(11):1203-1212

Robins PE, Lewis MJ, Simpson JH, Howlett ER, Malham SK (2014) Future variability of solute transport in a macrotidal estuary. Estuar Coast Shelf Sci 151:88-89

Schemel LE, Cox MH, Runkel RL, Kimball BA (2006) Multiple injected and natural conservative tracers quantify mixing in a stream confluence affected by acid mine drainage near Silverton, Colorado. Hydrol Process 20:2727-2743

Sharp EL, Parsons SA, Jefferson B (2006) Seasonal variations in natural organic matter and its impact on coagulation in water treatment. Sci Total Environ 363(1-3):183-194

Sholkovitz ER, Boyle EA, Price NB (1978) Removal of dissolved humic acids and iron during estuarine mixing. Earth Planet Sci Lett 40(1):130-136

Simpson JH, Vennell R, Souza AJ (2001) The salt fluxes in a tidally energetic estuary. Estuar Coast Shelf Sci 52:131-142

Sobczak WV, Cloern JE, Jassby AD, Muller-Solger AB (2002) Bioavailability of organic matter in a highly disturbed estuary: the role of detrital and algal resources. Proc Natl Acad Sci USA 99(12):8101-8105

Spencer RGM, Ahad JME, Baker A, Cowie GL, Ganeshram R, Upstill-Goddard RC, Uher G (2007) The estuarine mixing behaviour of peatland derived dissolved organic carbon and its relationship to chromophoric dissolved organic matter in two North Sea estuaries (UK). Estuar Coast Shelf Sci 74(1-2):131-144

Stutter MI, Richards S, Dawson JJC (2013) Biodegradability of natural dissolved organic matter collected from a UK moorland stream. Water Res 47(3):1169-1180

Taylor PG, Townsend AR (2010) Stoichiometric control of organic carbon-nitrate relationships from soils to the sea. Nature 464(7292): 1178-1181

Temnerud J, Seibert J, Jansson M, Bishop K (2007) Spatial variation in discharge and concentrations of organic carbon in a catchment network of boreal streams in northern Sweden. J Hydrol 342(1-2):72-87

Uher G, Hughes C, Henry G, Upstill-Goddard RC (2001) Nonconservative mixing behavior of colored dissolved organic matter in a humic-rich, turbid estuary. Geophys Res Lett 28(17):3309-3312 
Weishaar JL, Aiken GR, Bergamaschi BA, Fram MS, Fujii R, Mopper K (2003) Evaluation of specific ultraviolet absorbance as an Indicator of the chemical composition and reactivity of dissolved organic carbon. Environ Sci Technol 37(20):4702-4708

Wickland KP, Aiken GR, Butler K, Dornblaser MM, Spencer RGM, Striegl RG (2012) Biodegradability of dissolved organic carbon in the Yukon River and its tributaries: seasonality and importance of inorganic nitrogen. Glob Biogeochem Cycle 26:2012gb004342
Worrall F, Moody CS (2014) Modeling the rate of turnover of DOC and particulate organic carbon in a UK, peat-hosted stream: including diurnal cycling in short-residence time systems. J Geophys Res Biogeosci 119(10):1-2

Wu FC, Mills RB, Cai YR, Evans RD, Dillon PJ (2005) Photodegradation-induced changes in dissolved organic matter in acidic waters. Can J Fish Aquat Sci 62(5):1019-1027 